\title{
Assessing the comparative advantage of broiler production in Peninsular Malaysia using policy analysis matrix
}

\begin{abstract}
Broiler meat is the largest and cheapest protein source in Malaysia. Using the policy analysis matrix (PAM), this study examines the comparative advantage of broiler production in Peninsular Malaysia. Three hundred and ten farms in Peninsular Malaysia were involved in a field survey. The results of the domestic resource cost (DRC) show that Malaysia has a comparative advantage in all scales of broiler production. Sensitivity analysis indicates that the changes in input prices have a significant effect on comparative advantage. Nonetheless, the industry should reduce its dependence on corn-based feed, which is expensive and has an unstable price, to increase competitiveness in further securing its comparative advantage.
\end{abstract}

Keyword: Broiler; Policy analysis matrix; Comparative advantages; Peninsular Malaysia; DRC 